CLINICAL STUDY

\title{
TLR4 gene polymorphisms: evidence for protection against type 2 diabetes but not for diabetes-associated ischaemic heart disease
}

\author{
A C Manolakis ${ }^{1}$, A N Kapsoritakis ${ }^{1}$, E K Tiaka ${ }^{1}$, A Sidiropoulos ${ }^{2}$, A Gerovassili ${ }^{2}$, M Satra ${ }^{2}$, D Vamvakopoulou ${ }^{1}$, \\ $\mathrm{F}_{\text {Tsiopoulos }}{ }^{1}$, N Papanas ${ }^{3}$, I Skoularigis ${ }^{4}, \mathrm{~S}$ P Potamianos ${ }^{1}$ and N Vamvakopoulos ${ }^{2}$ \\ Departments of ${ }^{1}$ Gastroenterology and ${ }^{2}$ Molecular Biology and Genetics, School of Medicine, University of Thessaly, 41110 Mezourlo, Larissa, Greece, \\ ${ }^{3}$ Second Department of Internal Medicine, School of Medicine, Democritus University of Thrace, Alexandroupolis, Greece and ${ }^{4}$ Department of Cardiology, \\ School of Medicine, University of Thessaly, 41110 Mezourlo, Larissa, Greece
}

(Correspondence should be addressed to S P Potamianos who is now at University Hospital of Larissa, 41110 Mezourlo, Larissa, Greece; Email:spotam@med.uth.gr)

\begin{abstract}
Objective: Several factors either predisposing or protecting from the onset of diabetes mellitus type 2 (DM2) have been proposed. Two specific polymorphisms of toll-like receptor 4 (TLR4; Asp299Gly and Thr399Ile) have recently been identified either as candidate protector genes against DM2 and associated neuropathy or risk alleles for the manifestation of diabetic retinopathy. The impact of these alleles on the risk for ischaemic heart disease (IHD) is controversial while their role in diabetesassociated IHD has never been studied.

Design and methods: In order to clarify the potential impact of TLR4 polymorphisms on the predisposition for DM2 as well as on diabetes-related IHD vulnerability, the distribution of the mutant TLR4 Asp299Gly and Thr399Ile alleles in 286 DM2 patients and 413 non-DM2 controls with or without IHD, was examined.

Results: Mutant alleles were predominantly detected in 79/413 non-diabetic individuals versus 15/286 DM2 patients $(P<0.0001)$. The rates of positivity for mutant alleles were similar among diabetic patients with or without IHD (7/142 vs 8/144, $P>0.1)$, whereas they proved different among non-diabetic individuals with or without IHD (39/145 vs 40/268, $P=0.004)$. Following multivariate analysis, the difference between diabetic and non-diabetic subjects, with regard to TLR4 mutations alone, remained significant $(P=0.04)$.

Conclusions: Mutant TLR4 alleles confer protection against DM2. However, their presence does not seem to play any role, protective or aggravating, in the manifestation of IHD either in diabetic or in non-diabetic individuals.
\end{abstract}

European Journal of Endocrinology 165 261-267

\section{Introduction}

Among the various endocrine disorders, the biggest challenge is without doubt diabetes mellitus (DM), especially type 2 (DM2; Mendelian Inheritance in Man/MIM ID \#125853), a disease of global dissemination and steadily increasing incidence throughout the western societies $(1,2)$. Several risk factors have been associated with the onset of DM2, including family history of DM, ethnicity, obesity and polycystic ovary disease (2-5). However, only few factors have been found to induce protection against DM and its complications, i.e. nephropathy, retinopathy, and ischaemic heart disease (IHD) (2-6). Among these, specific polymorphisms of toll-like receptor 4 (TLR4) were quite recently proposed as being protective against DM2 (6).
Toll (meaning amazing, in German)-like receptors represent an ancient host defence pathway, and human toll, a type 1 transmembrane protein, is an essential immunological component linking innate and acquired immunity, while at the same time playing a crucial role in pathogen recognition. Located on 9q33.1, human TLR4 (MIM +603030) is a widely studied representative of the TLR family and a key receptor for the recognition of Gram-negative bacteria, fungi, viruses, high-mobility group box-1 (HMGB1) alarmin protein secreted by dying tumour cells and saturated fatty acids (7-10). Being distributed in macrophages, endothelial cells, brain, gut, liver, pancreas, muscle and adipose tissues (10), TLR4 and its polymorphic alleles have been linked with several disorders, including DM. An up-regulation of TLR4 levels has been associated with the increased inflammatory response recorded in 
DM (11) and has been proposed as the link between inflammation and atherosclerosis in diabetic patients (12). As for the TLR4-related genetic variations, it has been proposed that the TLR4 Asp299Gly allele confers protection against DM2 (6), as well as diabetic neuropathy (13), while the TLR4 Thr3991le allele against diabetic neuropathy alone (13). On the contrary, the presence of both mutant alleles has been linked to early onset of diabetic retinopathy (14). In view of their impact on IHD, it has been shown that the two alleles may be related to a decreased risk for the onset of IHD, although the results from the available literature are conflicting (15-17).

\section{Methods}

\section{Study population}

'Mutant' TLR4 Asp299Gly or D299G (MIM 603030. 001) and Thr399Ile or T399I (MIM 603030.002) polymorphic alleles were genotyped in 699 individuals: 286 with DM2 and 413 without DM2 (controls). Of the 286 diabetic patients, 142 were also diagnosed with IHD, compared with 145 of the 413 controls. All groups were sex, age and smoking frequency matched $(P>0.1$ in all cases). DM2 patients and IHD controls were recruited and followed at the University Hospital of Larissa, Greece. The remaining group of non-IHD controls consisted 268 randomly selected healthy blood donors. The demographic and clinical characteristics of study participants are summarised in Table 1. Diagnosis of DM2 was based on the criteria of the American Diabetes Association (18), whereas for IHD participants, diagnosis was established on angiographic documentation, the American College of Cardiology criteria (19) and the Joint European Society of Cardiology and American College of Cardiology Committee consensus (20) (Table 2). Patients with stable angina were not included. All study participants were Caucasians, inhabiting the area of central Greece (Thessaly).

\section{Genotypic analysis}

DNA isolation DNA isolation was performed as described previously (21). In brief, genomic DNA was extracted from $200 \mu \mathrm{l}$ whole blood using an automated DNA extraction device (Magtration System 12GC).

PCR amplification The sequence around the TLR 4 Asp299Gly and Thr3991le polymorphisms was amplified using a PCR-based protocol. The used primers were designed using Primer 3 software (www.justbio.com). Program-derived pair of forward 5'-TCTAGAGGGCCTGTGCAATT- $3^{\prime}$ and reverse $5^{\prime}$-TGAAACTCACTCATTTG-

Table 1 Study population demographics, clinical characteristics and routine examination values. Values are presented as absolute numbers or mean \pm S.D.

\begin{tabular}{|c|c|c|c|c|}
\hline & \multicolumn{2}{|c|}{ DM2 } & \multicolumn{2}{|c|}{ Controls } \\
\hline & IHD & Non-IHD & IHD & Non-IHD \\
\hline Age (years) & $63.1 \pm 5.4$ & $62.3 \pm 5.7$ & $62.4 \pm 5.2$ & $62.2 \pm 5.1$ \\
\hline \multicolumn{5}{|l|}{ Sex } \\
\hline Male & 81 & 82 & 92 & 175 \\
\hline Female & 61 & 62 & 53 & 93 \\
\hline \multicolumn{5}{|l|}{ Smoking } \\
\hline Yes & 74 & 70 & 78 & 123 \\
\hline No & 68 & 74 & 67 & 135 \\
\hline \multicolumn{5}{|l|}{ Hypertension } \\
\hline Yes & 86 & 85 & 103 & 187 \\
\hline No & 56 & 59 & 42 & 81 \\
\hline BMl $\left(\mathrm{kg} / \mathrm{m}^{2}\right)$ & $26.2 \pm 3.3$ & $25.8 \pm 3.5$ & $25.1 \pm 3$ & $25.2 \pm 3.2$ \\
\hline DM duration (years) & $12.9 \pm 4.4$ & $12.1 \pm 4.3$ & - & - \\
\hline \multicolumn{5}{|l|}{ Family history of IHD } \\
\hline Yes & 65 & 63 & 53 & 90 \\
\hline No & 77 & 81 & 92 & 178 \\
\hline Cholesterol (mmol/l) & $5.18 \pm 0.57$ & $5.1 \pm 0.6$ & $5.21 \pm 0.62$ & $5.13 \pm 0.64$ \\
\hline $\mathrm{HDL}(\mathrm{mmol} / \mathrm{l})$ & $0.97 \pm 0.16$ & $1 \pm 0.18$ & $1.06 \pm 0.17$ & $1.08 \pm 0.19$ \\
\hline $\mathrm{LDL}(\mathrm{mmol} / \mathrm{l})$ & $2.7 \pm 0.26$ & $2.69 \pm 0.2$ & $2.73 \pm 0.18$ & $2.7 \pm 0.2$ \\
\hline Triacylglycerol (mmol/l) & $1.9 \pm 0.1$ & $1.89 \pm 0.17$ & $1.85 \pm 0.19$ & $1.84 \pm 0.2$ \\
\hline $\mathrm{HbA} 1 \mathrm{c}^{\star}$ & $0.077 \pm 0.006$ & $0.076 \pm 0.007$ & $0.045 \pm 0.012$ & $0.046 \pm 0.014$ \\
\hline Glucose (mmol/l) & $8.8 \pm 1.1$ & $8.7 \pm 1.1$ & $5 \pm 1$ & $4.8 \pm 1.09$ \\
\hline \multicolumn{5}{|l|}{ Statin therapy } \\
\hline Yes & 84 & 48 & 97 & 32 \\
\hline No & 58 & 96 & 48 & 236 \\
\hline
\end{tabular}

* Proportion of total haemoglobin.

DM2, diabetes mellitus type 2; IHD, ischaemic heart disease; BMI, body mass index. 
Table 2 Criteria used for the diagnosis of DM2 and IHD.

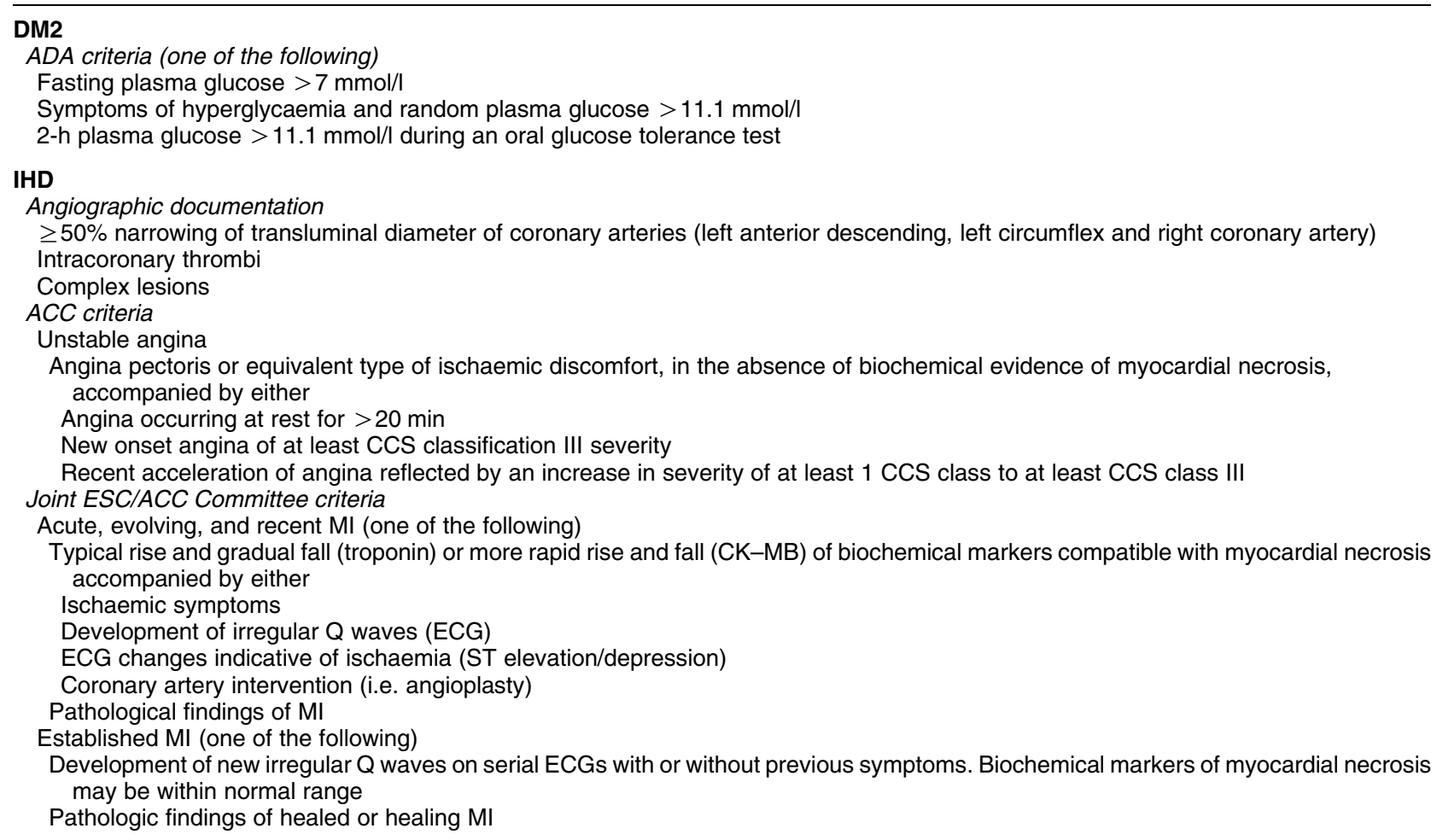

DM2, diabetes mellitus type 2; IHD, ischaemic heart disease; ADA, American Diabetes Association; CCS, Canadian Cardiovascular Society; ESC, European Society of Cardiology; ACC, American College of Cardiology; MI, myocardial infarction; CK-MB, creatine kinase-myocardial band; ECG, electrocardiogram.

TTTCAA-3' primers generated a 438 bp-long fragment. The PCR products were generated using a PTC-200 MJ Research Thermocycler (MJ Research, Inc., Waltham, MA, USA) after 35 cycles of DNA denaturation at $95^{\circ} \mathrm{C}$ for $30 \mathrm{~s}$, annealing at $55^{\circ} \mathrm{C}$ for $30 \mathrm{~s}$ and extension at $72{ }^{\circ} \mathrm{C}$ for $30 \mathrm{~s}$. The reaction mixture consisted $20 \mathrm{mM}$ Tris-HCl (pH 8.4), 50 mM KCl, $1.5 \mathrm{mM} \mathrm{Mg}^{2+}, 200 \mu \mathrm{M}$ of each dNTP, 1.5 U Taq DNA polymerase (Invitrogen) and $15 \mathrm{pmol}$ of each primer.

Sequence analysis Purification of the PCR products was performed using the PureLink PCR purification kit (Invitrogen). Automated cycle sequencing for both strands was performed with the ABI analyser using the BigDye Terminator Cycle Sequencing kit (Applied Biosystems). Products were electrophoresed on the Applied Biosystems 3130 Genetic Analyzer (Applied Biosystems). The obtained sequences were aligned using Sequencher PC software (Gene Codes Corp., Ann Arbor, MI, USA) with normal sequences from GenBank (GenBank accession number: NM_138554) and examined for the presence of mutations. All nucleotide numbers refer to the wild-type cDNA.

\section{Routine examinations}

HbA1c levels were calculated using the DCA 2000 device (Bayer Corporation). Total cholesterol, high-density lipoprotein (HDL) and triacylglycerol levels were determined using an enzymatic colorimetric assay and commercially available kits (Olympus Diagnostics, GmbH, Hamburg, Germany), whereas for low-density lipoprotein (LDL), the Friedewald's formula was applied.

\section{Statistical analysis}

Statistical analysis included the use of Student's $t, \chi^{2}$ (to exclude deviations from the Hardy-Weinberg equilibrium), Fisher's exact and ANOVA tests. Instead of using the parameter $D$, an estimate of linkage (dis)equilibrium which tends to become affected by allele frequency, an adjusted, for allele frequencies correlation coefficient $r$ between the studied loci, was calculated using the equation: $r=D / \sqrt{ }$ product of allele frequencies. During comparison, whenever a level of significance $P<0.05$ was recorded in univariate, multivariate analysis was also performed. Multivariate testing was carried out using multiple logistic regression while considering, a priori, age, sex, smoking, family history of IHD, body mass index (BMI), hypertension, HbA1c, lipoprotein and triacylglycerol levels, statin therapy as well as diabetes duration and applying a backward selection process as potential confounding factors. Due to the fact that patients were often under $>1$ anti-hypertensive/anti-diabetic agent or switched from one agent to another, in order to perform the most 
accurate possible analysis, these diverse agents were examined while also taking into account the period or duration of treatment with each drug. However, this led to a great heterogeneity and, during statistical analysis, low overall model performance (or overall model fit, expressed as adjusted $R^{2}$ for logistic regression models). Thus, the strongest 'predictors' (or confounding factors) in our statistical analysis, hypertension, not antihypertensive therapies, and the presence/absence of DM and DM 'regulation', reflected in HbA1c levels, were ultimately included, yielding the best possible adjusted $R^{2}$. The analyses described above were carried out using the MedCalc 10.2.0.0 statistical software (MedCalc Software bvba, Mariakerke, Belgium). Using the CaTS 0.0.2 power calculator, it was estimated that based on the current size and case-control ratio of our population, the detection of differences, in terms of mutant allele distribution, could be performed with a power exceeding $80 \%$ ( $\approx 96 \%$ ) at the 0.05 level of significance.

\section{Ethical considerations}

The study was approved by the ethics committee of the University of Thessaly Medical School. Informed consent was obtained from all individuals participating in the study.

\section{Results}

Mutant TLR4 Asp299Gly and Thr399Ile alleles were detected in 94/699 individuals $(13.4 \%$ of study population) and in linkage disequilibrium (100\% cosegregation, $r=1$ ). The studied alleles were found to be in Hardy-Weinberg equilibrium. The relative frequencies of both alleles were 15/286 in DM patients compared to $79 / 413$ in the control group (odds ratio (OR): $0.23,95 \%$ confidence intervals $(95 \% \mathrm{CI})$ : 0.13-0.42, $P<0.0001$; Fig. 1). When the mutant alleles were studied in our population while evaluating only the presence or absence of IHD, a near-trend difference was recorded among subjects with (46/287) or without IHD (48/412) (OR: 1.45 , 95\% CI: $0.94-$ $2.24, P=0.1)$. The distribution of mutant alleles among DM2 patients with $(7 / 142)$ or without IHD (8/144) was similar (OR: $0.88,95 \% \mathrm{CI}: 0.3-2.5, P>0.1$ ), while in the control group (without DM2) it was 39/145, in the subgroup with, versus $40 / 268$, in the subgroup without IHD (OR: 2.1, 95\% CI: 1.28-3.45, $P=0.004$; Fig. 2). Thus, the recorded difference in mutant allelic frequency between IHD and non-IHD subjects resulted from the control group (non-DM2) exclusively. On the contrary, no statistically significant differences were recorded when the presence of mutant TLR4 alleles was examined under the light of unstable angina and myocardial infarction, separately or the angiographically documented coronary atheroma burden (number of diseased arteries, occlusion rates, occlusion

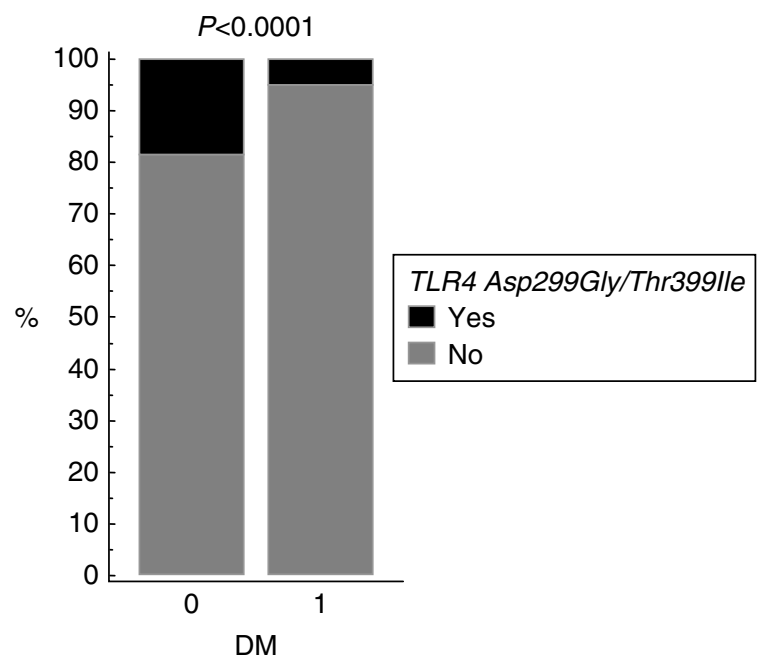

Figure 1 Relative distribution of the cosegregated TLR4 Asp299Gly and Thr399lle alleles in subjects with $(\mathrm{DM}=1)$ or without $(\mathrm{DM}=0) \mathrm{DM} 2$.

sites $-P>0.1$, in all cases). Similarly, no significant interactions were recorded between TLR4 and treatment modalities (anti-hypertensive or DM-related medication) or glucose levels $(P>0.1)$.

In multivariate analysis, the negative association of TLR4 Asp299Gly and Thr399Ile polymorphisms with DM2 remained statistically significant after adjusting for confounding factors, although the level of significance decreased (OR: 0.21, 95\% CI: 0.07-0.92, $P=0.04$; adjusted $\left.R^{2}=0.87\right)$. As for the increased presence of the studied genes in the non-DM2 group with IHD, the significance of this finding was completely attenuated after adjustment for age, sex, smoking, family history of IHD, BMI, hypertension, HbA1c, lipoprotein and triacylglycerol levels as well as statin therapy (OR: 0.94, 95\% CI: 0.83-1.08, P>0.1; adjusted $\left.R^{2}=0.89\right)$. An overlook of the fluctuations of OR and 95\% CIs is presented in Fig. 3.

\section{Discussion}

The relative distribution of 'mutant' TLR4 Asp299Gly and Thr399Ile alleles was assessed in individuals with or without DM2 while at the same time investigating potential implications for the onset of DM-related IHD. In agreement with previous reports $(6,22)$, our findings suggest that carriers of these mutant alleles are more protected against DM2. As for the impact of the mutant alleles on IHD susceptibility, our data show that compared with carriers of wild-type alleles, they exhibit similar rates of DM-associated IHD. In order to understand the significance of the present finding, additional lines of evidence have to be discussed.

TLR4 Asp299Gly and Thr399Ile mutant alleles seem to have originated in Africa in an environment 


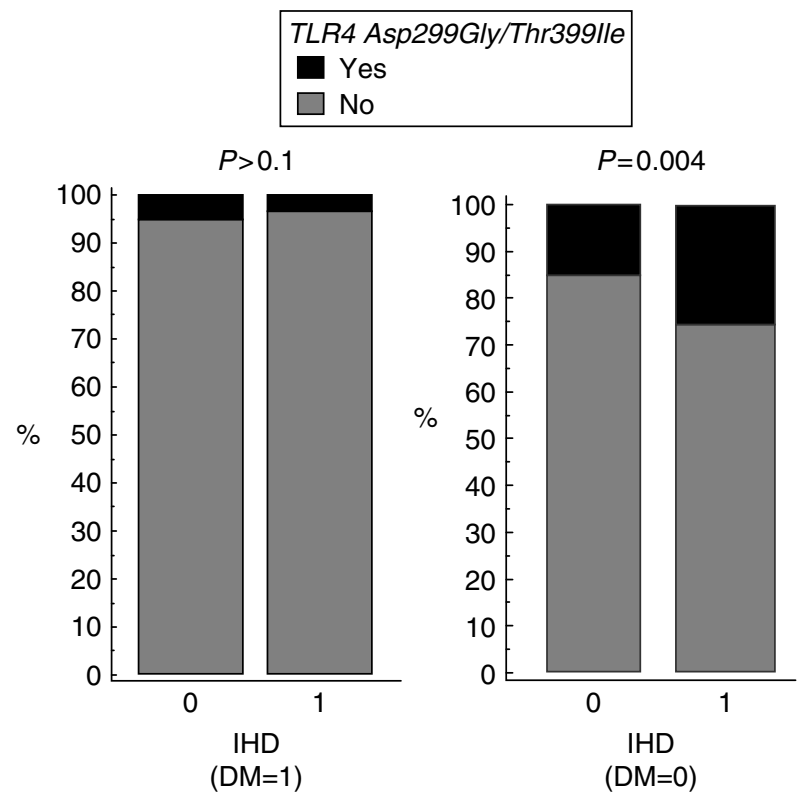

Figure 2 Comparative distribution of mutant (dark grey) and wild-type (light grey column) alleles in DM2 patients $(\mathrm{DM}=1)$ and non-DM2 controls $(\mathrm{DM}=0)$ with $(\mathrm{IHD}=1)$ or without $(\mathrm{IHD}=0)$ ischaemic heart disease (IHD).

where malaria represented a major evolutionary pressure: first the Asp299Gly and later on the Thr399Ile allele $(7,8)$. The frequency of these alleles varies from $0 \%$ in Polynesian, Southeast-Asian and native SouthAmerican populations to $5-9 \%$ in Indo-Europeans (7, 8). In a Plasmodium spp.-infested environment the Asp299Gly, although increasing susceptibility to infections as well as the risk of septic shock, it induced protection against malaria-associated mortality $(7,8)$. However, the 'addition' of the Thr3991le mutant allele, as in Indo-Europeans, reduced the risk for septic shock to rates similar to those observed in carriers of the wild-type alleles $(7,8)$. This simultaneous presence - linkage disequilibrium - of both mutant alleles was a useful addition, as the presence of the Asp299Gly alone would result in greater susceptibility during the plague, typhoid fever and influenza outbreaks in Europe $(7,8)$. These selective forces acted vigorously in the area of Central Greece, site of origin of our study group, where malaria rates were high until the 1960s, a fact also reflected in the increased frequency of haemoglobinopathies, in our region compared to others, in Greece $(23,24)$. Thus, as previously shown and confirmed in our study, the percentage of the population carrying the mutant alleles is higher $(\approx 13.5 \%)$ (25-27) in comparison with other European - except for Dutch, Romanian (14\%) and Basque (18\%) - or other native Greek populations (6\%) (8).

Being in linkage disequilibrium, these mutant alleles are inherited in a cosegregated manner and are present in offspring in the form of a Asp299Gly/Thr3991le haplotype $(7,8)$. Thus, experts on the subject advise to address any issues related to these alleles while considering the existence of six distinct haplotypes: wild-type/wild-type, wild-type/Asp299Gly, wild-type/ Thr399Ile, Asp299Gly/Thr399Ile, Asp299Gly/Asp 299Gly and Thr399Ile/Thr399Ile (8). The double mutant Asp299Gly/Thr399Ile state, although initially considered indistinguishable to the wild-type genotype $(7,8)$, has been shown to alter the structure of TLR 4 itself, leading to a problematic binding of ligands (28). This structural/functional irregularity ultimately seems to be responsible for a more blunt immune response, i.e. a reduced production of $\operatorname{IgA}$ against microbial targets, i.e. anti-Helicobacter pylori (26), anti-outer membrane porin, anti-chitobioside antibodies (29), compromised recognition of apoptosis signals during anti-cancer therapy (9) or the presence of decreased functional TLR4 levels (30). An activation of functional TLR4 in insulin target tissues, however, by fatty acids - dietary or endogenous - has been shown to exert proinflammatory responses, i.e. excessive production of cytokines, reactive oxygen species, eicosanoids and activation of kinases, which in turn lead to insulin desensitisation (10). When bearing in mind these characteristics along with the evidence linking this increased TLR4 functionality with persistent inflammation and subsequent DM2 $(11,31)$, it is within reason to assume that those carrying a TLR4 suppressive polymorphism, capable of attenuating these phenomena, might eventually be more protected against the disease.

Although, a similar mutant TLR4-mediated protective effect against IHD vulnerability would be expected, because a hyporesponsive TLR4 could also suppress the inflammatory processes involved in atherogenesis and plaque destabilisation, this was not verified in our study. This lack of protection, also recorded in other studies, seems to underline the importance of bearing in mind that the altered TLR4 functionality is a 'double-edged sword' $(16,17,32)$. Therefore, it is possible that the benefits from a less profound inflammatory response within the vascular wall could be compensated by, for instance, an increased susceptibility to infections and subsequently to a
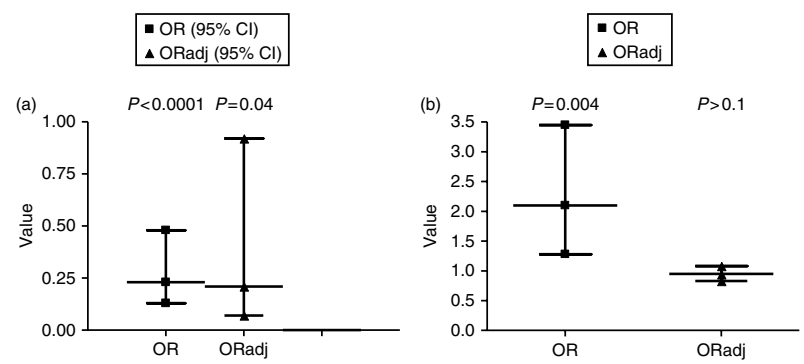

Figure 3 Graph of the odds ratio (OR) and $95 \% \mathrm{Cl}$ of the TLR4 Asp299Gly/Thr399lle for the induction of (a) DM2 and (b) DM2-independent IHD, before (OR) and after (ORadj) adjustment for confounding. 
greater pathogen burden, which has been associated with $\operatorname{IHD}(7,8,33)$. In addition, any beneficial effect induced by mutant TLR4 alleles may be outweighed by the presence of well-established risk factors for IHD (smoking, hypertension, DM and so on). Within certain limitations, primarily involving the lower frequency of studied alleles among DM2 patients, our findings do not support an additional role for the TLR4 Asp299Gly and Thr399Ile genes with respect to DM2-related IHD, because no differences were observed regarding IHD susceptibility in DM2 patients, carrying the mutant or the wild-type alleles. Due to this phenomenon, although our data are not suggestive of any implications of TLR4 genetic variations for DM-linked IHD, large population studies are required, preferably in populations where these mutations are markedly frequent, i.e. in Basques (8), before this hypothesis can be utterly rejected.

When considering the aforementioned data on the protective potential of TLR4 mutations, an obvious paradox seems to emerge. Despite the relatively high frequency of protective TLR4 alleles, in the western populations, an increasing DM2 incidence is being recorded $(1,2)$. This phenomenon may be due to the impact of lifestyle/environmental factors (fat and calorie-rich, nutrient-poor diet, low levels of exercise and so on), on the development of DM2 (1-3), the contribution of other genetic loci on the diversity of DM2 susceptibility, among ethnicities $(4,34,35)$ and the currently 'fixed' mutant TLR 4 genetic background primarily influenced by neutral genetic drift $(7,8)$, because traditional selective pressures (infections) have been relieved as a result of aggressive antimicrobial practices, i.e. water disinfection, use of antibiotics, etc.

In conclusion, it seems that individuals simultaneously carrying the TLR4 Asp299Gly and Thr399Ile polymorphic alleles are more protected against the onset of DM2, although they exhibit similar rates of DM-associated IHD compared with those with the wild-type alleles. These results, originating from a study focusing on specific TLR4 genetic mutations, need to be confirmed by further studies applying next-generation genome wide array techniques, so that the earlier limitations of non-additivity (gene-gene or geneenvironment interactions) (35) also influencing the distribution of TLR4 mutations, even among IndoEuropeans, could be overcome.

\section{Declaration of interest}

The authors declare that there is no conflict of interest that could be perceived as prejudicing the impartiality of the research reported.

\section{Funding}

This research did not receive any specific grant from any funding agency in the public, commercial or not-for-profit sector.

\section{Acknowledgements}

The authors would like to thank Prof. Filippos Triposkiadis, Department of Cardiology, University of Thessaly, School of Medicine, for providing consultation and data for IHD patients.

\section{References}

1 Wild S, Roglic G, Green A, Sicree R \& King H. Global prevalence of diabetes: estimates for the year 2000 and projections for 2030. Diabetes Care 200427 1047-1053. (doi:10.2337/diacare.27.5.1047)

2 Lirussi F. The global challenge of type 2 diabetes and the strategies for response in ethnic minority groups. Diabetes Metabolism Research and Reviews 201026 421-432. (doi:10.1002/dmrr.1105)

3 Wilson PW, Meigs JB, Sullivan L, Fox CS, Nathan DM \& D'Agostino RB Sr. Prediction of incident diabetes mellitus in middle-aged adults: the Framingham Offspring Study. Archives of Internal Medicine 2007167 1068-1074. (doi:10.1001/archinte. 167.10.1068)

4 Talmud PJ, Hingorani AD, Cooper JA, Marmot MG, Brunner EJ, Kumari M, Kivimäki M \& Humphries SE. Utility of genetic and non-genetic risk factors in prediction of type 2 diabetes: Whitehall II prospective cohort study. BMJ 2010340 b4838. (doi:10.1136/ bmj.b4838)

5 Moran LJ, Misso ML, Wild RA \& Norman RJ. Impaired glucose tolerance, type 2 diabetes and metabolic syndrome in polycystic ovary syndrome: a systematic review and meta-analysis. Human Reproduction Update 201016 347-363. (doi:10.1093/humupd/ dmq001)

6 Kolek MJ, Carlquist JF, Muhlestein JB, Whiting BM, Horne BD, Bair TL \& Anderson JL. Toll-like receptor 4 gene Asp299Gly polymorphism is associated with reductions in vascular inflammation, angiographic coronary artery disease, and clinical diabetes. American Heart Journal 2004148 1034-1040. (doi:10. 1016/j.ahj.2004.05.049)

7 Ferwerda B, McCall MB, Verheijen K, Kullberg BJ, van der Ven AJ, van der Meer JW \& Netea MG. Functional consequences of toll-like receptor 4 polymorphisms. Molecular Medicine 200814 346-352. (doi:10.2119/2007-00135.Ferwerda)

8 Ferwerda B, McCall MB, Alonso S, Giamarellos-Bourboulis EJ, Mouktaroudi M, Izagirre N, Syafruddin D, Kibiki G, Cristea T, Hijmans A, Hamann L, Israel S, ElGhazali G, Troye-Blomberg M, Kumpf O, Maiga B, Dolo A, Doumbo O, Hermsen CC, Stalenhoef AF, van Crevel R, Brunner HG, Oh DY, Schumann RR, de la Rúa C, Sauerwein R, Kullberg BJ, van der Ven AJ, van der Meer JW \& Netea MG. TLR4 polymorphisms, infectious diseases, and evolutionary pressure during migration of modern humans. PNAS $2007 \mathbf{1 0 4}$ 16645-16650. (doi:10.1073/pnas.07048 28104)

9 Apetoh L, Ghiringhelli F, Tesniere A, Obeid M, Ortiz C, Criollo A, Mignot G, Maiuri MC, Ullrich E, Saulnier P, Yang H, Amigorena S, Ryffel B, Barrat FJ, Saftig P, Levi F, Lidereau R, Nogues C, Mira JP, Chompret A, Joulin V, Clavel-Chapelon F, Bourhis J, André F, Delaloge S, Tursz T, Kroemer G \& Zitvogel L. Toll-like receptor 4-dependent contribution of the immune system to anticancer chemotherapy and radiotherapy. Nature Medicine $2007 \mathbf{1 3}$ 1050-1059. (doi:10.1038/nm1622)

10 Kim JJ \& Sears DD. TLR4 and insulin resistance. Gastroenterology Research and Practice 20102010 139-149. (doi:10.1155/2010/ 212563)

11 Dasu MR, Devaraj S, Park S \& Jialal I. Increased toll-like receptor (TLR) activation and TLR ligands in recently diagnosed type 2 diabetic subjects. Diabetes Care 201033 861-868. (doi:10.2337/ dc09-1799)

12 Hodgkinson CP, Laxton RC, Patel K \& Ye S. Advanced glycation end-product of low density lipoprotein activates the toll-like 4 receptor pathway implications for diabetic atherosclerosis. Arteriosclerosis, Thrombosis, and Vascular Biology $2008 \mathbf{2 8}$ 2275-2281. (doi:10.1161/ATVBAHA.108.175992) 
13 Rudofsky G Jr, Reismann P, Witte S, Humpert PM, Isermann B, Chavakis T, Tafel J, Nosikov VV, Hamann A, Nawroth P \& Bierhaus A. Asp299Gly and Thr399Ile genotypes of the TLR4 gene are associated with a reduced prevalence of diabetic neuropathy in patients with type 2 diabetes. Diabetes Care 2004 27 179-183. (doi:10.2337/diacare.27.1.179)

14 Buraczynska M, Baranowicz-Gaszczyk I, Tarach J \& Ksiazek A. Toll-like receptor 4 gene polymorphism and early onset of diabetic retinopathy in patients with type 2 diabetes. Human Immunology 200970 121-124. (doi:10.1016/j.humimm.2008.12.003)

15 Ameziane N, Beillat T, Verpillat P, Chollet-Martin S, Aumont MC, Seknadji P, Lamotte M, Lebret D, Ollivier V \& de Prost D. Association of the toll-like receptor 4 gene Asp299Gly polymorphism with acute coronary events. Arteriosclerosis, Thrombosis, and Vascular Biology 200323 e61-e64. (doi:10.1161/01.ATV. 0000101191.92392.1D)

16 Holloway JW, Yang IA \& Ye S. Variation in the toll-like receptor 4 gene and susceptibility to myocardial infarction. Pharmacogenetics and Genomics 200515 15-21. (doi:10.1097/01213011200501000-00003)

17 Koch W, Hoppmann P, Pfeufer A, Schömig A \& Kastrati A. Toll-like receptor 4 gene polymorphisms and myocardial infarction: no association in a Caucasian population. European Heart Journal 200627 2524-2529. (doi:10.1093/eurheartj/ehl231)

18 American Diabetes Association. Standards of medical care in diabetes - 2009. Diabetes Care 200932 (Supplement 1) S13-S61.

19 Cannon CP, Battler A, Brindis RG, Cox JL, Ellis SG, Every NR, Flaherty JT, Harrington RA, Krumholz HM, Simoons ML, Van De Werf FJ, Weintraub WS, Mitchell KR, Morrisson SL, Brindis RG, Anderson HV, Cannom DS, Chitwood WR, Cigarroa JE, CollinsNakai RL, Ellis SG, Gibbons RJ, Grover FL, Heidenreich PA, Khandheria BK, Knoebel SB, Krumholz HL, Malenka DJ, Mark DB, Mckay CR, Passamani ER, Radford MJ, Riner RN, Schwartz JB, Shaw RE, Shemin RJ, Van Fossen DB, Verrier ED, Watkins MW, Phoubandith DR \& Furnelli T. American College of Cardiology key data elements and definitions for measuring the clinical management and outcomes of patients with acute coronary syndromes. A report of the American College of Cardiology task force on clinical data standards (acute coronary syndromes writing committee). Journal of the American College of Cardiology 200138 2114-2130. (doi:10.1016/ S0735-1097(01)01702-8)

20 The Joint European Society of Cardiology/American College of Cardiology Committee. Myocardial infarction redefined - a consensus document of The Joint European Society of Cardiology/American College of Cardiology Committee for the redefinition of myocardial infarction. European Heart Journal $2000 \mathbf{2 1}$ 1502-1513. (doi:10.1053/euhj.2000.2305)

21 Satra M, Vamvakopoulou DN, Sioutopoulou DO, Kollia P, Kiritsaka A, Sotiriou S, Antonakopoulos G, Alexandris E, Costantoulakis P \& Vamvakopoulos NC. Sequence-based genotyping HPV L1 DNA\&RNA transcripts in clinical specimens. Pathology, Research and Practice 2009205 863-869. (doi:10. 1016/j.prp.2009.07.020)

22 Bagarolli RA, Saad MJ \& Saad ST. Toll-like receptor 4 and inducible nitric oxide synthase gene polymorphisms are associated with type 2 diabetes. Journal of Diabetes and its Complications $2010 \mathbf{2 4}$ 192-198. (doi:10.1016/j.jdiacomp.2009.03.003)

23 Stamatoyannopoulos G \& Fessas P. Thalassaemia, glucose-6 phosphate dehydrogenase deficiency, sickling, and malarial endemicity in Greece: a study of five areas. BMJ 19641 875-879. (doi:10.1136/bmj.1.5387.875)
24 Samara M, Chiotoglou I, Kalamaras A, Likousi S, Chassanidis C, Vagena A, Vagenas C, Eftichiadis E, Vamvakopoulos N, Patrinos GP \& Kollia P. Large scale-population genetic analysis for hemoglobinopathies reveals different mutation spectra in Central Greece compared to the rest of the country. American Journal of Hematology 200782 634-636. (doi:10.1002/ajh.20889)

25 Giaglis S, Papadopoulos V, Kambas K, Doumas M, Tsironidou V, Rafail S, Kartalis G, Speletas M \& Ritis K. MEFV alterations and population genetics analysis in a large cohort of Greek patients with familial Mediterranean fever. Clinical Genetics $2007 \mathbf{7 1}$ 458-467. (doi:10.1111/j.1399-0004.2007.00789.x)

26 Manolakis AC, Kapsoritakis AN, Tiaka EK, Satra M, Gerovassili A, Tsiompanidis I, Vamvakopoulos N \& Potamianos SP. Impact of TLR-4 polymorphisms on circulating levels of antibodies against Helicobacter pylori. Helicobacter 201015 481-482. (doi:10.1111/ j.1523-5378.2010.00785.x)

27 Speletas M, Kalala F, Mitroulis I, Papadopoulos V, Merentiti V, Germenis AE \& Ritis K. TLR2 and TLR4 polymorphisms in familial Mediterranean fever. Human Immunology $2009 \mathbf{7 0} 750-753$. (doi:10.1016/j.humimm.2009.05.004)

28 Rallabhandi P, Bell J, Boukhvalova MS, Medvedev A, Lorenz E, Arditi M, Hemming VG, Blanco JC, Segal DM \& Vogel SN. Analysis of TLR4 polymorphic variants: new insights into TLR4/ MD-2/CD14 stoichiometry, structure, and signaling. Journal of Immunology 2006177 322-332.

29 Henckaerts L, Pierik M, Joossens M, Ferrante M, Rutgeerts P \& Vermeire S. Mutations in pattern recognition receptor genes modulate seroreactivity to microbial antigens in patients with inflammatory bowel disease. Gut 200756 1536-1542. (doi:10. 1136/gut.2007.125468)

30 Prohinar P, Rallabhandi P, Weiss JP \& Gioannini TL. Expression of functional D299G.T399I polymorphic variant of TLR4 depends more on coexpression of MD-2 than does wild-type TLR4. Journal of Immunology $2010 \mathbf{1 8 4} 4362-4367$. (doi:10.4049/ jimmunol.0903142)

31 Schulthess FT, Paroni F, Sauter NS, Shu L, Ribaux P, Haataja L, Strieter RM, Oberholzer J, King CC \& Maedler K. CXCL10 impairs beta cell function and viability in diabetes through TLR4 signaling. Cell Metabolism 20099 125-139. (doi:10.1016/j. cmet.2009.01.003)

32 Morange PE, Tiret L, Saut N, Luc G, Arveiler D, Ferrieres J, Amouyel P, Evans A, Ducimetiere P, Cambien F, Juhan-Vague I \& PRIME Study Group. TLR4/Asp299Gly, CD14/C-260T, plasma levels of the soluble receptor CD14 and the risk of coronary heart disease: the PRIME study. European Journal of Human Genetics 200412 1041-1049. (doi:10.1038/sj.ejhg.5201277)

33 Manolakis AC, Kapsoritakis AN, Tiaka EK \& Potamianos SP. Chronic persistent infections as a risk factor for ischemic heart disease: the Helicobacter pylori model. In Horizons in World Cardiovascular Research, vol 2, ch 8, pp 165-182. Ed. E Bennington. New York: Nova Science Publishers, 2010.

34 Vimaleswaran KS \& Loos RJ. Progress in the genetics of common obesity and type 2 diabetes. Expert Reviews in Molecular Medicine 201012 e7. (doi:10.1017/S1462399410001389)

35 McCarthy MI \& Zeggini E. Genome-wide association studies in type 2 diabetes. Current Diabetes Reports 2009 9 164-171. (doi:10.1007/s11892-009-0027-4)

Received 23 May 2011

Accepted 31 May 2011 